\title{
How does digital technology impact on the co- production of local services? Evidence from a childcare experience
}

\begin{abstract}
By combining the traditional literature on public administration and public management with that on Human-Computer Interaction, this paper contributes to the debate about how digital technology can support the co-creation of public value in co-production activities. We examine two case studies of participatory requirements elicitation for a technology aimed to support the co-design of a childcare service. By observing that the digital technology is requested to satisfy "ancillary values" that constrain how the coproduction is operated, our analysis clarifies how the instrumental and the institutional roles of the technology intersect and fulfill each other.
\end{abstract}

Keywords: New Public Governance co-production, digital technology, policy-design, affordance lens

Mattia Casula (Ca' Foscari University of Venice, mattia.casula@hotmail.it)

Chiara Leonardi (FBK, cleonardi@fbk.eu)

Massimo Zancanaro (University of Trento and FBK, massimo.zancanaro@unitn.it/zancana@fbk.eu)

\section{Introduction}

A recent debate in the public governance literature concerns the impact of digital tools on public service delivery, and how technology can support the co-creation of public value among multiple actors involved in co-production activities (Osborne et al., 2016; Sorrentino et al., 2018; Clark et al., 2013). This paper contributes to this debate by addressing the following research question: how can technology support the co-creation of public value in the co-production of local services?

The role of digital technology in supporting co-production activities is crucial, but it is still largely understudied (with some notable exceptions like Meijer, 2012; Paletti, 2018; Moon, 2018, Lember et al., 2019). In order to furnish deeper understanding of this role, in this article we propose an exploratory study intended to understand how technology should be designed in order to support the co-creation of public value. We explored the role that a digital platform could play in the process of childcare services co-creation in two different communities - a neighborhood (among peers) and a private organization (among employees and endorsed by the HR department)—.

Childcare is an interesting example of a local public service (see for example Pestoff, 2011): amid widespread budget cuts that are also involving municipal childcare services, European families increasingly need to devise alternative solutions facilitated by the use of digital artefacts. Although scholars have provided many different examples of direct contributions by parents, in economic, 
political, pedagogical and social terms, to the value created by childcare facilities throughout Europe (Pestoff, 2011), previous studies have only focused on traditional forms of co-production, and the potential role of technology in supporting the co-creation of public value has not yet been investigated.

Our two case studies were chosen to compare and contrast this specific service in two different instances. In fact, in recognizing that value added in co-production activities has several dimensions that differ between private sector and public sector organizations (see Bovaird and Loeffler, 2012), our analysis explored how technology should help the co-creation of public value in contexts of a different nature. In both cases, a group of citizens (who were also employees in the second case study) were involved in a participatory process intended to determine the needs and values concerning this service and how to proper co-produce it

The first case study took place in a neighborhood. It involved peer citizens and the local public administration. The second case study took place in a private organization: it involved employees and the human resources department. The reason for choosing these two case studies was to compare a truly public service (the first case study) with a slightly different case in which an organization was involved and the parents concerned were also employees. This approach yielded better understanding of the differences between the public sector and the private sector organizations in both the conceptualization of the service and the demands on digital technologies.

A participatory approach was used to understand the different perspectives of the actors and stakeholders involved (Casula, 2015). Among the several activities that were organized, there were some specific ones aimed at designing a digital tool to support this service. In this article, we use the insights of this participatory process to investigate how technology helps the cocreation of public value in a local service. Thus, in presenting and discussing these case studies, we do not look at the technology in use (as done for example by Meijer, 2012) but rather at how the actors imagined that the technology should be designed.

Furthermore, the requests and desiderata for the technology are discussed not in terms of its functionalities (i.e. the technical features) but in terms of its affordances (i.e. the tasks, needs or goals that a specific technology makes it possible to perform, satisfy or achieve). This affordances lens (Faraj and Azad, 2012), combined with the public administration and public management literature on co-production, enables us to discuss how ICT impacts on the co-creation of the public value in a co-production activity in a novel way.

A key point in our analysis is that the digital technology is required to satisfy what in this article we call "ancillary values" that constrain how the co-production is performed. This aspect better clarifies how the instrumental and institutional roles of the technology (Meijer, 2012) intersect with and fulfill each other.

The paper is structured as follows: Section 2 presents the theoretical background about the role of digital technology in co-production of public value and the affordances lens; Section 3 briefly describes the case studies; Section 4 presents the analysis of-the two case studies; Section 5 concludes and discusses how technology can support the co-creation of public value. 


\section{Theoretical Background}

\section{Co-production, co-creation and public value}

Even if it has been current for decades (Pestoff, 2011), the concept of co-production has experienced a revival during the past decade, contextually with the evolution of the traditional idea of a public administration totally managed or coordinated by the public authorities with topdown relationships toward the New Public Governance paradigm (Capano et al. 2012; Capano et al. 2015; Casula 2017a; Kooiman, 2003; Osborne, 2006, 2011).

In this context, scholars have become interested in analyzing how the constant interaction among the multiple actors that are involved in these different "co-production activities" can cocreate public value (Alford, 2009), with the latter notion being conceptualized "partly in terms of the satisfaction of individuals who [enjoy desirable outcomes] and partly in terms of the satisfactions of citizens who have seen a collective need, fashioned a public response to that need, and thereby participated in the construction of a community" (Moore 1995, 47). As a result, "service" is now conceived as a process through which value is added to any service or product (Osborne et al., 2016): value is co-created through the transformation of service components at the point of co-production (Vargo and Lusch, 2006).

Due to the establishment of these new models of governance for public services delivery, the concept of co-production has recently been redesigned as well (Honingh et al., 2018). Until the emergence of the NPG paradigm, in fact, the concept of co-production traditionally referred to "the mix of activities that both public service agents and citizens contribute to the provision of public services. The former are involved as professionals, or regular producers, while citizen production is based on voluntary efforts by individuals and groups to enhance the quality and/or quantity of the services they use" (Parks et al. 1981, 1999). Hence, in this context, the term "coproduction' was used to explain different phenomena and aspects of participation by citizens and/or the third sector in different phases of public service delivery (Rønning et al. 2013; Brandsen et al. 2018). In the past decade, however, there have been several attempts to define the concept of co-production more clearly and to distinguish it from similar ones, such as co-creation and citizen engagement. This has generated a proliferation of definitions of the concept that make it difficult to establish a common research agenda (e.g. Alford, 2014; Howlett and Ramesh, 2017; Nabatchi et al., 2017; Osborne and Strokosch, 2013; Sicilia et al. 2016; Sicilia et al. 2019; Webster and Leleux, 2018). While recognizing the merits of other definitions of co-production and cocreation of value, we shall adopt a commonly used definition provided by Osborne et al. (2016). We believe, in fact, that their definition is more suitable to the purpose of our work since it takes into account not only the instrumental nature of the concept, but also its value elements. By referring to the "voluntary or involuntary involvement of public service users in any of the design, management, delivery and/or evaluation of public services" (Osborne et al. 2016, 640), for such users co-production can have both a different nature and a different locus: while the nature of coproduction refers to voluntary or involuntary participation of citizens/users in the public service delivery process, the locus refers to the public services both as entities in their own right and as part of holistic service delivery systems. By combining these two elements (nature and locus of 
co-production), Osborne et al. elaborated four ideal types of values that are co-created by users, as follows:

- the traditional co-production of public services, where public value is co-created by citizens that co-produce public services with the public authority;

- the co-design of public services, where public value is voluntarily co-created by citizens involved in improvement of the performance of an existing public service;

- the co-construction of public services, where public value is the result of the interaction of the service user with the service system as a whole to construct his/her 'lived experience' of the service;

- the co-innovation of public services, where public value is the result of the voluntary involvement of service users in the co-innovation of new forms of public service delivery within service systems.

By adopting Osborne et. al.'s (2016) conceptualization of co-production, this article contributes to the emerging literature on the possible impact of digital technology on co-creation of value in coproduction activities for the co-design of public services, i.e. where the locus of co-production is the individual service, while its nature is voluntary.

\section{ICT in the co-production of public value}

Albert Meijer (2012) claims that in co-production services, technology matters in both instrumental and institutional terms. He argues that technology facilitates new practices of co-production, and that technology transforms these practices into more social and playful interactions. He then discusses how the value of technology depends on the policy domain, institutional situation and existence of citizen communities. While agree on the specific example, we contend that this value of technology can be conceptualized more precisely by resorting to the concept of affordance. Specifically, we claim that the values related to the the co-produced service depend on the policy domain, institutional situation and existence of citizen communities (among other things) while the specific value of a technology in support of the service can be assessed by the extent to which it "affords" those values related to the service. For example, Meijer's reference to playful interactions may be misleading: an affordance that enables playful interaction is important when playfulness is an ancillary value in the service but it can be detrimental in numerous other cases.

Lember (2017) discusses how digital technologies affect co-production, and he argues that there is a great deal of ambiguity in how digital technologies shape co-production because they often frame it and at times reduce it. He also suggests (following Kitchin, 2016) that co-creating the technologies underpinning the co-production processes may be useful to alleviate those issues. Indeed, our approach was to co-create a specific technology for the co-production of childcare in two similar but distinct case studies. Furthermore, we tried to construct a general framework by which to understand how technology helps reduce ambiguity.

Paletti (2018) proposes a comprehensive framework in which to consider the four different perspectives on how digital technology mediates co-production: (i) the legal and policy-making 
perspective, (ii) the organizational perspective, (iii) the technical perspective, (iv) the performance-oriented perspective. Our conceptualization elaborates what Paletti calls the 'technical perspective', which refers to how technologies should be designed to enable coproduction and involves both the aspects related to infrastructures and those related to the involvement of several external actors. In this regard, we elaborated the latter aspect, which is currently underestimated in Paletti's framework. We believe that the affordances lens can make it possible to link the technical perspective with organizational goals and the evaluation of services.

Lember et al. (2019) propose an analytical framework to account for the conditions in which digital technologies impact on various elements of co-production and co-creation. The framework is based on the assumption that four elements can be identified in co-creation/co-production (establishing interaction, motivating the people involved, bringing resources, and shared decisionmaking) while digital technologies are defined by four instrumental characteristics (taken from Aceto et al., 2018), i.e. sensing, communication, processing, and actuation. Our case studies demonstrate that, although important, digital technologies could not be accounted only in terms of instrumental characteristics (as also noted by Meijer, 2012), but implicit support on values is crucial. We believe that because the affordances lens departs from a purely instrumental view of digital technology, it makes it possible to complement and extend this framework. By adopting a definition of co-production and co-creation propounded by Brandsen and Honing (2016; 2018), the framework proposed by Lember et al. (2019) focuses only on instrumental aspects. In our approach, we leverage Osborne et al.'s (2016) definition, and we acknowledge that digital technology has an impact on value aspects as well.

\section{The affordances lens to technology}

In investigating how technology may support the co-creation of public value, we employ the affordances lens approach in which the unit of analysis is the entanglement between the people purposes and the technology capabilities (Majchrzak and Markus, 2013; Fayard and Weeks, 2014; Volkoff and Strong, 2017).

The concept of affordance was initially defined by Gibson (1979) in ecological psychology as the behavioral possibilities or opportunities for action offered to animals by the environment. In this respect, an affordance is a relation between the animal and the environment (Chemero, 2003). This notion was later used in the analysis of human/computer interaction to characterize the aspects of an artifact that suggest how it should be used (Norman, 1988). It has been argued that in the design of artifacts, the relational notion of affordances is more fundamental than the notions of function or feature (Maier and Fadel, 2009; Faraj and Azad, 2012). This is because the relational nature of the concept of affordances helps explain two frequently observed aspects of technology in use: (i) people may not realize the possibility of action offered by an artifact; and (ii) people may use an artifact to perform actions not intended by designers. 


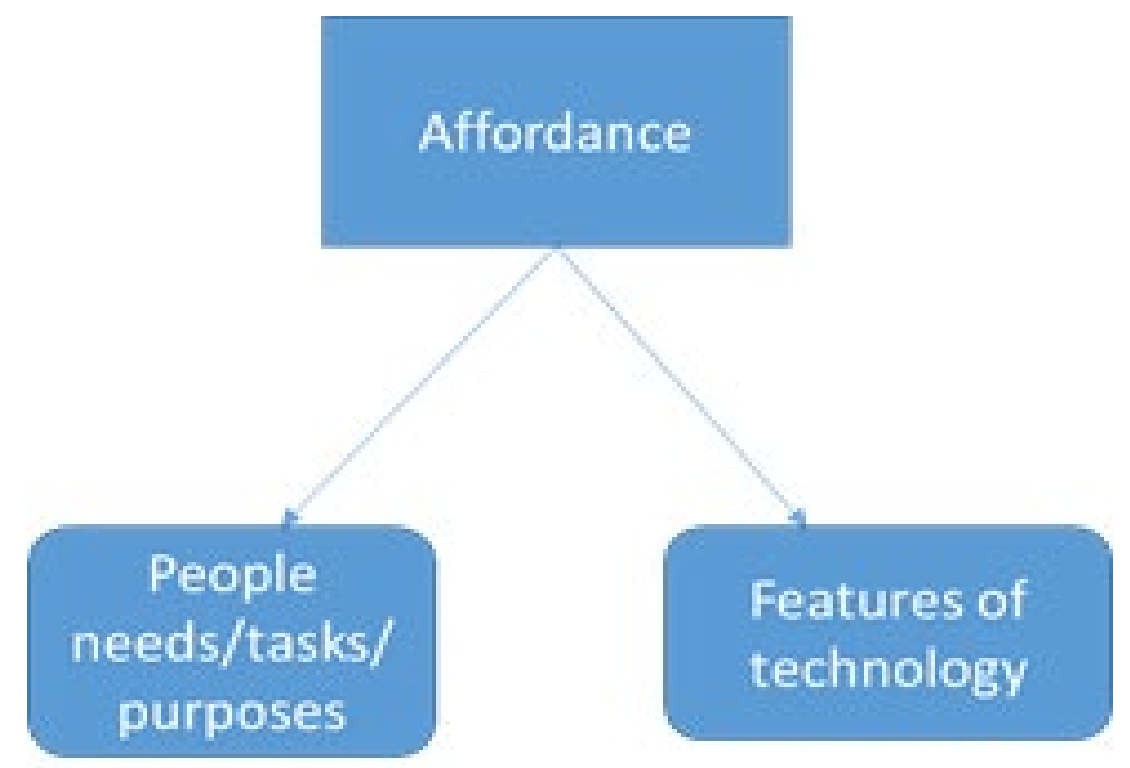

Figure 1 Affordances are relations between people needs/tasks/purposes and features of technology

In the field of Human-Computer Interaction, the notion of affordance was meant to help designers make artifacts more usable and intuitive (McGrenere and Ho, 2000). More recently, the Information System has seen growing interest in applying the original Gibsonian view. This relates to usefulness rather than usability, the aim being to investigate how technology is selected and used, either by individuals or groups of organizational actors, and the resulting changes in organizational processes and structures (Volkoff and Strong, 2017).

The affordances lens is a theoretical approach to investigating the material nature of technology (in particular digital technology) and its relationships with its social context of use. According to this approach, affordances are not just the perceptual features of an artifact but more generally the relations between people needs/tasks/purposes and features of technology. In this respect, affordances are best expressed in terms of action verbs or gerunds ("share knowledge" or "information sharing", Majchrzak and Markus, 2013).

\section{Values in design of technology}

The roles of values in how technology is designed, used and appropriated has been long discussed in the human/computer interaction field (see Friedman et al. 2017). In this regard, we define values as "what is important to people in their lives, with a focus on ethics and morality" (following Friedman et al. 2017).

In our analysis, we employed a version of the "value scenarios" method (Nathan et al. 2008; Friedman et al. 2017) to involve a number of stakeholders in discussing the impact that a technology aimed at supporting collaborative childcare may have on the value of the service. The scenario-based design approach (Carroll, 2000; Rosson and Carroll, 2002) is a technique to foster the participation of stakeholders in definition of the requirements of an envisaged system. It 
consists in presenting and discussing stories, called 'scenarios', that represents a specific problem or technology in use with different purposes (Bødker, 2000). Each scenario comprises the following elements in a narrative or visual form: (i) user's goals and motivations, (ii) tasks that need to be accomplished, (iii) interactions (social + mediated), (iv) a specific context (temporal, spatial, and cultural). The advantage of presenting scenarios rather than involving users in actual discussing the solutions come from the fact that scenarios are at the same time concrete and flexible tools (Carroll, 2000). They are concrete since they allow presenting interpretations of design solutions. They are flexible since easy to revise or elaborate them. .

In our study, the use of scenarios was twofold. On the one hand, we wanted to assess how a digital technology may support the process of co-production, that is, the affordances of the technology. On the other hand, we sought to elicit what aspects of this specific co-production were deemed important and should not be hindered by the technology? (that is, values implied in the service and in its co-production). An example of a scenario presented to and discussed with parents is the following:

"Hannah (38) is a single parent. She has a son aged eight and a daughter aged ten. Because schools break up for Easter, she is looking for childcare over the week of the Easter holidays. While talking to Meredith, a colleague of hers, she discovered a new online platform that can be used to organize childcare among colleagues, and Meredith is an enthusiastic user of this scheme. Hannah decides to give it a try and asks Meredith for more information about the platform. Meredith promptly sends an email to Hannah, including an invitation to join the platform. Hannah receives the email and sees that there are other parents looking for childcare during the Easter break. She also sees that the group is already scheduling activities for the week of Easter. They have already found the location (an area of the ACME company organized for hosting children, with a big table, a library and an open space for play), she also notices that some colleagues have already marked their availability on the shared calendar."

As can be noted, the scenario contains explicit references to a digital platform, but it leaves several specific details underspecified. This allows participants to discuss the two perspectives freely: the use of technology and its impact on their practices. With this approach, we tried to gain better understanding of the aspects of technology that extend beyond the instrumental role in supporting co-production.

\section{Two case studies of co-production of childcare}

We involved two communities in Italy in a set of participatory activities aimed at: (i) understanding the feasibility of such a new approach and (2) eliciting the requirements of a digital platform to support it.

Our two case studies represent two different examples of communities in which a co-production approach to childcare may be instantiated.

Bologna case study. In Bologna, citizens were involved through local groups of parents living in the same neighborhood. Social NGOs were also directly engaged in the study. In particular, in the initial set-up phase, a number of meetings were organized with local associations that provide social welfare services; a registered NGO active in promoting social inclusion with an intercultural 
and gender perspective; and an informal network running a local time bank. The aim of these meetings was to frame the concrete participation of these associations within the project and to collect their suggestions for the involvement of further organizations in the project, as well to promote parents' engagement in the study. During a second phase, other local associations involved in the childcare ecosystem took part in the study: for this purpose, a new time bank, and three further parent associations were contacted.

Trento case study. In Trento, on the other hand, we involved a small network of private companies and public organizations that were already experimenting with novel forms of childcare provision. Among other things, the HR departments of these companies are proposing summer camps on the organizations' premises for employees' children (as a form of family-life balance opportunity). They also promote employees' participation, as volunteers, in the summer camps by valuing employees participation in formal terms (e.g. integrating the activities within working hours) and by offering discounts on the registration of their children. For the HR departments of these companies, these initiatives and the participation of employees are viewed as part of their corporate social responsibility plan. This context has been the starting point for a participatory process aimed at evolving these summer camp initiatives toward a full co-production approach.

\section{Method}

As said above, in our analysis we employed the scenario-based design (Carroll, 2000; Nathan et al. 2008) to explore participants' values, to assess design requirements, and to investigate problematic aspects of a technology to support the co-production of childcare. The scenarios were based on a number of dimensions elicited from the extant literature on co-production of childcare.

\section{Research dimensions}

In light of the public administration and public management literature, we first investigated the type of exchange best suited to this type of collaboration on childcare. In some volunteering schemes, time can be exchanged for the same amount of time, while in others it may be just donated. We analyzed how participants perceived this feature, exploring the values behind timesharing and prompting respondents to reflect on risks that this feature may have, as well on opportunities. Several studies (Ozanne, 2010, Carroll et al., 2017) suggest that time banking approaches sustain social inclusion that creates opportunities for new relationships, strengthens bonds among community members, and fosters skills acquisition for self-sufficiency. Instead, other studies (see for example, Bellotti et al., 2014) also report limitations of the "timebanking" approach, for instance showing that some values are not supported by the "bank" metaphor, such as community development and social care. The values and motivations in taking part to these volunteer exchanges may vary from altruistic and solidarity-based values to motivations related to personal growth.

Another research dimension that emerges from the literature is trust and the related values connected with community development. Studies on peer-to-peer exchange have shown that a number of challenges exist: focusing on the childcare context, Lampinen et al. (2015) discussed 
how the main barrier to the adoption of a peer-to-peer exchange within a community of single parents was related "to balancing efforts to attract a critical mass of users with the desire for trusted relationships between network members". Moreover, a sense of community should exist in order for members to trust each other and engage in social exchange (Butts 2013). Technology may negatively impact on this aspect: for example, the need to explicitly share personal information may raise a number of issues when children are involved (Perentis 2017). Similarly, personal profiles, feedbacks and users' evaluations may be key aspects for developing online trust (Wang and Emurian, 2005). But they may also be detrimental to the notion of solidarity on which volunteer communities are often based (Vlachokyriakos, 2017).

Finally, regarding parents' motivations for participating in communities of this type, studies suggest that there are heterogeneous motivations beyond altruism (Casula, 2017b): for example, the development of skills and personal contacts (Carroll et al., 2017), practical motivations, economic drivers, and the improvement of the quality of a service through direct participation (Pestoff 2012).

\section{Participants and research approach}

Our first step consisted in assessing the needs of the user group involved with respect to the dimensions described above. Semi-structured interviews (10 interviews in Trento and 11 in Bologna) were conducted with the goal of identifying the respondents' attitudes toward new collaborative approaches to improve work/life balance, previous experiences with peer-to-peer support among parents, and technologies already used to coordinate with other parents for reciprocal support.

The second step consisted in a series of workshops organized both in Trento and Bologna with parents and stakeholders to reflect on the features of a possible digital platform and consider its benefits and drawbacks. Twenty-five (25) people were involved in Trento and 31 in Bologna.

During the workshops, the participants were divided into small groups, each coordinated by a facilitator. Discussion of the technology was driven by four scenarios explicitly prepared to prompt discussions among the potential users on the specific aspects of using a digital platform to coordinate with other parents in childcare provision. In total, four scenarios based on the dimensions outlined above were created. Each scenario presented a short story about a fictional character interacting with an under-specified technological platform to fulfill a task related to the planning or the coordination of a childcare activity. The stories were slightly different in the two case studies in order to account for the different contexts (a local community in Bologna and an organizational setting in Trento).

In particular, the scenarios were meant to explore the ecosystem of actors that should be activated to organize such initiatives: who is responsible for the platform? Who manages the groups? Who can support the coordination of camps? How can trust be sustained among members for this particular type of social exchange, where children are involved?

The data collected by means of the workshops consisted in short annotations written on post-its by the participants and later transcribed and analyzed using thematic analysis. 


\section{Analysis of the two case studies}

In this section, we present an analysis of the arguments used by the participants in the two case studies when discussing the pro and cons of the technology described in the scenarios.

The values of the participants emerged in the motivations (often prompted by the facilitators) that they provided for the need (or the absence of needs) regarding a functionalities.

Discussion about the functionalities was summarized in the analysis in terms of affordances. The use of the affordances lens enabled us to generalize the discussion about the technology with respect to the different functionalities considered.

\section{Values evidenced by the discussion}

In both Trento and Bologna, it emerged that the willingness to accept and participate in this type of alternative form of childcare was mediated by common ethical values that not only motivated but also defined the participation. These values were: (1) trust in the community and the individual belonging to the community; (2) active participation as a way to be part of the community; and (3) the importance of face-to-face encounters as the main means to be part of the community.

We call these values "ancillary" because they support the primary value of child-caring. Indeed, the existence of ancillary values has also been recognized (albeit without using this term) by Osborne and colleagues (2016): on discussing the meaning of value in co-creation, they write:

"[...] the 'value' to a customer of a meal in a restaurant is not a simple financial transaction - it is not an aggregation of the cost of the ingredients of the meal and the wages of the restaurant staff. Rather, its value to the customer is co-created by that customer and the restaurant at the point of consumption and includes not only the quality of the meal itself but the ambience of the restaurant, the actions of the restaurant staff and the impact of this upon the well-being of the customer"

We can recognize a similar structure of diverse values that compose and define the co-created value. As we will report in the following section, the discussions on the use of the technology eventually reinforced the importance of these ancillary values.

\section{Analysis of the affordances}

\section{Affordance 1: (affords the ability to ... ) managing group membership}

In Bologna, the participants were concerned that the distributed nature of groups might eventually bring untrustworthy individuals into the community. On the other hand, in Trento (where all the participants were employees of one of the organizations in the network), trust was mediated by the organizations, and many of the participants reported that they did not need to know personally who the volunteers were because they trusted the organizations and the quality of services. Indeed, several participants said that they would like know who take cares of their children but mainly to thank them for their volunteer work. 
When discussing the scenarios, in Bologna participants explicitly required a functionality whereby an application for new membership was approved by each and every member. On the other hand, there was no mention of such a requirement in Trento. Still, registration of new members was considered a core functionality in Trento too: some of the participants preferred to have a formal invitation by the HR department to join the groups. Although it words of mouths was suggested as more effective in promoting this kind of initiatives, the motivation for the request for the invitation was to reinforce the endorsement by the organization and to ensure trust.

In both communities, managing membership of the groups of parents was crucial. Although the perspectives were different, in both cases they were related to the concept of trust in a community of peers. In this respect, the same affordance (managing group membership) might be realized by means of different features: for example, in Bologna, the digital technology needs a functionality to alert the group members of the request of a new member and postponed the acceptance until everybody acknowledge while in Trento, this feature is not needed.

\section{Affordance 2: (affords the ability to ... ) valuing participation}

In Trento, a complete peer to peer informal approach was considered appropriate only for short and contingent support among colleagues. When a more structured and longitudinal commitment was foreseen, a synergy between the organizations/companies (HR departments) and the community of employees was necessary. In this respect, in Bologna it is different, the organizers of the community aimed at organizing in a complete peer to peer informal approach all the activities (although, they claim to prefer to rely on the family network for contingencies and lastminute emergencies.

In Bologna, the perspective was clearly inspired by the "time banking" model (Kakar, 2018): the community organizers seek in the technology a support to keep track and visualize (share) the information of individual contributions. In Trento, the perspective was completely different, The reference model was traditional childcaring augmented by voluntary participation, therefore, people did not like to track time as currency. Still, there was a need to recognize and praise those who volunteered for activities. The pressure to contribute was also strongly felt: some participants claimed that they would not be able to contribute with their time, and even if not required to do so they would like to contribute by other means (such as money or equipment).

Finally, in both communities there was a strong agreement to avoid open evaluation of activity or people. In Bologna, the participants reported that feedback should be allowed only in the case of objective negligence on the part of a member of the group (such as delays, absences or transgression of specific rules). Instead, in Trento, the role of super-partes of the HR department was considered sufficient to take care informally of these aspects.

In both communities, the value of participation was considered important. Despite the specific mechanisms with which the participation needs to be tracked and valued, we recognize the same affordance that needs to be offered by the technology to both communities: managing membership. Still, slightly different functionalities are needed: for example, visualization of time spent by each person should be avoided in Trento but it is required in Bologna. 


\section{Affordance 3: (affords the ability to ... ) negotiating dates and temporal constraints}

In both communities, the main need perceived by the participants was the negotiation of the dates on the calendar for activities. This problem was less strongly expressed in Trento: the participants, all working in a corporate context, were more used to the intricacies of time scheduling.

In both use cases, there were several requests not to have "another Facebook". Actually, many of the participants already used Facebook or messaging apps like WhatsApp to coordinate activities; but while these tools were considered effective for advertising the activity (and asking for support), and for communication during the activities, they were not considered useful for what concerns the management of temporal constraints among several people.

In both Trento and Bologna, it emerged as a strong value the possibility and the need of face-toface encounters. There is strong push to avoid that the digital technology facilitate online communication in spite of physical encounters. These encounters are of course needed for the childcare activities but are also an important part for setting trust, for solving conflicts and in general for solving organizational and logistic issues.

\section{Summing up}

It emerged from our participative process for designing a digital technology in support of group of parents that three affordances were considered as relevant by participants. A key point in our analysis is that the two technologies foreseen by the participants in the two use cases had similar affordances although the specific features discussed may seem different.

When looking at the level of affordances (i.e., using the affordances lens) the similarity between the technological requirements in the two groups became apparent. Furthermore, it became apparent that the three affordances were strictly related to the ethical "ancillary" values that emerged in the interviews.

Table 1 summarizes the affordances and the ancillary values they relate to.

Table 1. The affordances emerged in the participative process and their related values

\begin{tabular}{|l|l|l|}
\hline Affordance & affords the ability to .... & relates to ancillary value \\
\hline managing membership & $\begin{array}{l}\text { manage the group membership by means of specific } \\
\text { rules implicitly or explicitly negotiated in the community }\end{array}$ & trust \\
\hline valuing participation & $\begin{array}{l}\text { track individual participation to the various initiatives in } \\
\text { order to value or praise the individuals' provisions }\end{array}$ & participation \\
\hline
\end{tabular}




\begin{tabular}{|l|l|l|}
\hline negotiating calendars & $\begin{array}{l}\text { negotiate dates and temporal constraints among the } \\
\text { individuals involved in order to be able to schedule } \\
\text { meetings }\end{array}$ & face to face encounters \\
\hline
\end{tabular}

\section{Conclusion}

By combining the traditional literature on public administration and public management with that on Human-Computer Interaction, this paper fits into the debate on how digital technology can support the co-creation of public value in local service provision. Differently from other discussions in the literature (such as Meijer 2012; Paletti 2016, Paletti 2018) our work is not based on the provision of e-services, nor on technologies for smart cities (such as those mainly discussed in Lember, 2018). Rather, it focuses on a digital platform that transforms the provision of a local service by allowing citizens to co-produce it in a participatory way (by 'co-designing' it, to use the expression of Osborne et al., 2016). Furthermore, we discussed the properties of a technology being designed in a participatory process with potential users rather than a technology in use.

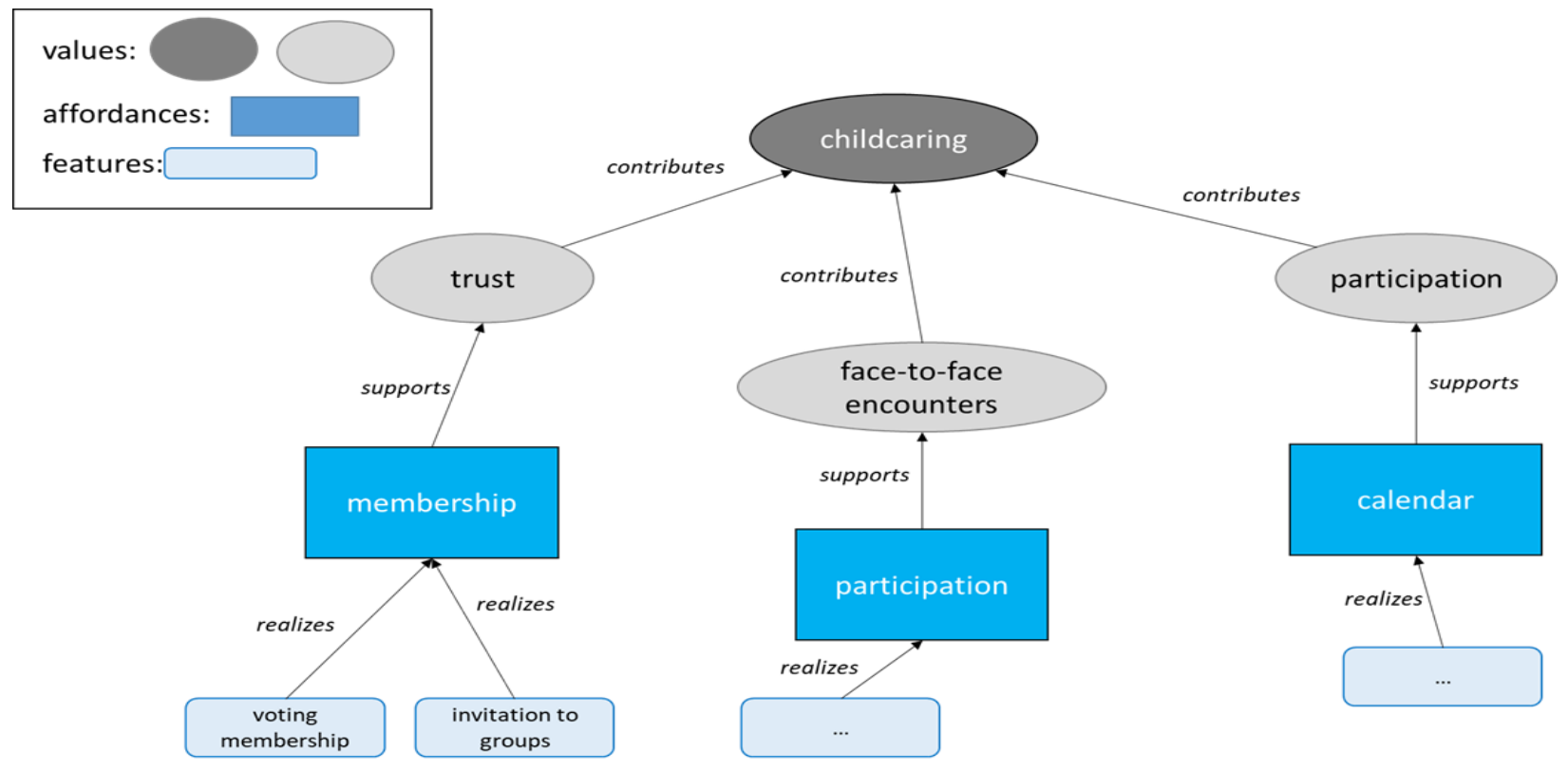

Figure 2 Summary of the relations between features and affordances as emerged in our two use cases.

We contribute to the current debate by analyzing digital technology in terms of affordances. With our use cases, we argued that this level of analysis made it possible to recognize some commonalities that would not have been apparent if we had focused on the mere functionalities of technology (that is, focusing only on the instrumental characteristics as in Lember et al. 2019). As illustrated in Figure 2, different features sometimes realize, from an instrumental point of view, the same affordance while focusing on the affordance level evidences the support that the technology provides to the ancillary (ethical) values. Those ancillary values, in turn, realize (as 
suggested by Osborne et al. 2016 with the restaurant example cited above) the value of the coproduced service.

In view of our research question, the value of collaborative childcaring should not be framed simply as an exchange between individuals to achieve personal goals. Indeed, besides instrumental needs (that in our cases might be classified in the "communication" characteristic in terms of the taxonomy proposed by Aceto et al. 2018 and used by Lember et al. 2019), the intrinsic values that sustain this exchange play a crucial role and the digital technology should properly support them. In our case studies, the crucial role of digital technology in supporting values and not only instrumental activities becomes apparent when the potential users (who were engaged in a participatory process to reflect on the design of the digital technology) came up with different functionalities (for example, a voting mechanism for membership with respect to invitation) for the same affordance (in this case the managing of membership). These differences in the functionalities required might be accounted for by recognizing a different perspective on some values that (often implicitly) underlie the main common value: in this case, the value of trust that was crucial in both cases but in slightly different ways (in the Bologna case, it was a crucial aspect related to privacy and safety while in the Trento case it was still crucial but largely delegated to the organization). In our analysis, we highlighted how the concept of "value" refers to the citizens' satisfaction with the service, as well as the extent to which it is able to meet their social and economic needs. By adopting affordances as the level of analysis, we could identify a number of ancillary - and interlinked - values, namely trust, face-to-face interaction and participation.

This level of analysis extends and complements the one proposed by Lember and colleagues (2019). Indeed, our digital technology, as envisaged by the participants, actually realizes all the four elements identified as part of the co-production/co-creation process by those authors. Nevertheless, in the proposed taxonomy of the characteristics of the technology that they take from Aceto et al. (2018), our technology only fits the "communication" characteristics. This limited view can only be overcome by recognizing that an instrumental role of the technology is not sufficient to account for the complexity of the scenario.

The limitation of a purely instrumental role was already discussed by Meijer (2012). But in our cases, it does not seem that an institutional role is enough either. We believe that by relating the affordances to the ancillary values, it emerged from our two studies that these roles are indeed functionally related to these values and intersect and fulfill each other. We may argue, although further research should be done, that some of the institutional roles that digital technology may play in a co-production process might be eventually related to ancillary values of the relation between the people and the institution: for example, the ancillary value of trust as emerged in the Trento case clearly depends on the relation between the employees and the organization, and therefore it may pertain to the sphere of an institutional role.

In summary, in the view of our insights, digital technology is meaningful when, beyond instrumental values, it fulfills goals related to ethical values that directly contribute to the value of the service (we called them ancillary values). We cannot claim that this is a general structure, and indeed there might be examples in which digital technology may directly contribute to the value of the service. For example, in the cases discussed in Meijer (2012) the technologies directly 
mediate the services, but they were cases of e-services. Yet, even for e-services, further analysis might have revealed a structure of ethical values related to the provision of the services discussed.

Of course, we do not claim that the findings emerged from our case studies can be generalized. We acknowledge, in fact, that our context was relatively simple because few stakeholders were involved and because users were in a deliberative position: that is, they could debate and decide for what and how the technologies should or could be used. There might be situations in which digital technologies do not support the realization of the values held by the users: our hypothesis is that in those cases, technology is perceived as less usable or less useful. Furthermore, in other situations, the need to account for several stakeholders may complicate the relationship between technology and service. Nevertheless, we believe that factoring in stakeholders' values and an analysis in terms of affordances lens may help in investigating the role of technology, and we believe that future research might still benefit from its application.

The participatory process described above will eventually be developed in an actual digital tool used for further studies. This will provide a context to investigate further how technology supports the co-creation of public value in local services by studying the technology in use (similarly to Mejier, 2012; Lember 2018; Paletti, 2018).

Future works should apply the affordances lens to investigate the co-innovation processes: that is, when the locus of the co-production is the service system and the nature of co-production is voluntary (Osborne et al., 2016). While this approach has similarities to our childcare use cases, our services are located at the level of individual service. In order to scale up the level of the system, future studies should plan to actively involve public administrations not in the implementation of childcaring but rather in the provision of a context in which self-organized, voluntary-based groups can co-produce the service. Furthermore, the new challenge is to design a digital tool to support the public administration staff to sustain the context enabling families to co-produce the service. Since this is a type of e-service, we will have a chance to assess the use of affordances lens approach.

\section{Acknowledgement}

The authors contributed equally to this work. The authors would like to thank the editors and the anonymous reviewers for their valuable advice and comments on previous versions of this article.

This work has been funded as part of the project Families Share, European Union's Horizon 2020 CAPS Grant agreement No 780783

\section{References}

Aceto, G., Persico, V. and Pescapé, A. (2018), The role of Information and Communication Technologies in Healthcare: Taxonomies, Perspectives, and Challenges, in "Journal of Network and Computer Applications”, 107, 125-154. https://doi.org/10.1016/j.jnca.2018.02.008 
Alford, A. (2009), Engaging Public Sector Clients - From Service-Delivery to Co-Production, London: Palgrave MacMillan.

Alford, J. (2014), The Multiple Facets of Co-Production: Building on the Work of Elinor Ostrom, in "Public Management Review", 16(3), 299-316.

Bellotti, V.M.E. et al. 2014. Towards Community-centered Support for Peer-to-peer Service Exchange: Rethinking the Timebanking Metaphor. In Proceedings of the SIGCHI Conference on Human Factors in Computing Systems (New York, NY, USA, 2014), 2975-2984.

Bødker, S. (2000), Scenarios in user-centred design - setting the stage for reflection and action, in "Interacting with Computers", 13(1), 61-75. https://doi.org/10.1016/S0953-5438(00)00024-2

Bovaird, S. and Loeffler, E. (2012), From Engagement to Co-Production: How Users and Communities Contribute To Public Services, in Pestoff et al. (eds) New Public Governance, the Third Sector, and Co-Production, London: Routledge.

Brandsen, T. and Honingh, M. (2016), Distinguishing different types of co-production: a conceptual analysis based on the classical definitions, in "Public Administration Review", 76(3), pp. $427-435$.

Brandsen, T., Honingh, M. (2018), Definitions of co-production and co-creation, in Brandsen T. and Honingh, M. (eds) Co-production and co-creation: Engaging citizens in public services, London: Routledge.

Brandsen, T., Verschuere, B., Steen T. (2018) (eds), Co-Production and Co-Creation: Engaging Citizens in Public Services, London: Routledge.

Butts, M.M. et al. 2013. How important are work-family support policies? A meta-analytic investigation of their effects on employee outcomes. Journal of Applied Psychology. 98, 1 (2013), 1-25. DOI:https://doi.org/10.1037/a0030389

Capano, G., Howlett, M.; Ramesh., M. (Ed.). Varieties of governance: dynamics, strategies, capacities. London: Palgrave Macmillan, 2015.

Capano, Gilberto; Rayner, J.; Zito, A. R. Governance from the bottom up: complexity and divergence in comparative perspective. Public Administration, v. 90, n. 1, p. 56-73, 2012.

Carroll, J. M. (2000), Five Reasons for Scenario-Based Design, in "Interacting with Computers", 13(1), 43-60.

Carroll, J. M., Shih, P. C., Han, K., \& Kropczynski, J. (2017). Coordinating Community Cooperation: Integrating Timebanks and Nonprofit Volunteering by Design. In "International Journal of Design". 11(1):51-63.

Casula, M. (2015), Opportunity Structures for Citizens' Participation in Italian Regions: A Case Study, in "Journal of Public Deliberation", Vol. 11: Iss. 2, Article 6. [ISSN: 1937-2841]. 
Casula, M. (2017a), Who Governs in (Local) Governance? Theoretical Considerations and Empirical Evidence, in "Revista de Administracao Publica-Brazilian Journal of Public Administration" [ISSN: 0034-7612].

Casula, M. (2017b), Adaptation or Transformation? Interpreting Participation in Times of Austerity in a (Old) Red Region, in "PArtecipazione e COnflitto. The Open Journal of Sociopolitical Studies, 10(3), pp. 1005-1036 DOI: 10.1285/i20356609v10i3p1005.

Chemero, A. (2003), An Outline of a Theory of Affordances, in "Ecological Psychology", 15(2), 181-195. https://doi.org/10.1207/S15326969ECO1502_5

Clark, B. Y., Brudney, J. L., and Jang, S.G. (2013). Coproduction of Government Services and the New Information Technology: Investigating the Distributional Biases, in "Public Administration Review", 73(5), 687-701.

Faraj, S., and Azad, B. (2012). The Materiality of Technology: An Affordance Perspective, in Leonardi, P.M., Nardi, B.A. and Kallinikos, J. (eds), Materiality and Organizing, Oxford, Oxford University Press.

Fayard, A.L., and Weeks, J. (2014). Affordances for Practice, in "Information and Organization", 24(4), 236-249. https://doi.org/10.1016/j.infoandorg.2014.10.001.

Friedman, B., Hendry, D. G., \& Borning, A. (2017). A Survey of Value Sensitive Design Methods. Foundations and Trends ${ }^{\circledR}$ in Human-Computer Interaction, 11(2), 63-125.

Gibson, J. J. (1979), The Ecological Approach to Visual Perception, Boston: Houghton Mifflin.

Howlett, M., \& Ramesh, M. (2017). The achilles heels of collaboration: Overcoming critical capacity deficits in collaborative governance arrangements? Paper presented at the NUS-FPZG UNESCO Chair Workshop on The Governance of Collaboration: Co-Production, Contracting, Commissioning and Certification, Dubrovnik, Croatia.

Kakar, A. K. (2018), Investigating Factors that Promote Time Banking for Sustainable Community Based Socio-Economic Growth and Development, in "Computers in Human Behavior", July, doi: 10.1016/j.chb.2018.07.034.

Kitchin, R. (2016). Reframing, reimagining and remaking smart cities, in "Programmable City Working Paper", n. 20. Available at: https://osf.io/preprints/socarxiv/cyjhg/.

Kooiman, J.. Governing as governance. London: Sage Publications, 2003.

Honingh, M., Bondarouk E., and Brandsen, T. (2018), Co-production in primary schools: a systematic literature review. In "International Review of Administrative Sciences", OnlineFirst. 
Lampinen, A. et al. 2015. Challenges to participation in the sharing economy: the case of local online peer-to-peer exchange in a single parents' network. Interaction Design and Architecture(s). IxD\&A, 24:16-32.

Lember, V. (2017), The Increasing Role of Digital Technologies in Co-production, The Other Canon Foundation and Tallinn University of Technology Working Papers in Technology Governance and Economic Dynamics 75, TUT Ragnar Nurkse Department of Innovation and Governance.

Lember, V. (2018), The Role of New Technologies in Co-production and Co-Creation, in Brandsen, T., Steen, T. and Verschuere, B. (eds) Co-production and co-creation: engaging citizens in public service delivery, London and New York: Routledge.

Lember, V., Brandsen, T. and Tõnurist, P. (2019, FirstView), The Potential Impacts of Digital Technologies on Co-Production and Co-Creation, in "Public Management Review", 1:22

McGrenere, J., and Ho, W. (2000). Affordances: Clarifying and Evolving a Concept, in " Proceedings of Graphics Interface”, Montreal.

Meijer, A. (2012), Co-Production in an Information Age, in Pestoff, V., Brandsen, T., and Verschuere, B. (eds), "New Public Governance, the Third Sector and Co-production", New York: Routledge.

Maier, J. R. A., and Fadel, G. M. (2009), Affordance Based Design: a Relational Theory for Design, in "Research in Engineering Design", 20(1), 13-27. https://doi.org/10.1007/s00163-0080060-3

Majchrzak, A., and Markus, M.L. (2013), Technology Affordances and Constraints in Management Information Systems (MIS). In E. Kessler (eds), Encyclopedia of Management Theory. SAGE Publications, Inc.

Moon, M. J. (2018). Evolution of Co-production in the Information Age: Crowdsourcing as a Model of Web-Based Co-production in Korea, in "Policy and Society", 37(3), 294-309. https://doi.org/10.1080/14494035.2017.1376475

Moore, M. (1995), Creating Public Value. Cambridge, MA: Harvard University Press.

Nabatchi, T., Sancino, A., and Sicilia, M. (2017), Varieties of Participation in Public Services: The Who, When, and What of Coproduction, in "Public Administration Review", 77 (5), 766-776. doi:10.1111/puar.12765.

Nathan, L. P., Friedman, B., Klasnja, P., Kane, S. K., \& Miller, J. K. (2008). Envisioning systemic effects on persons and society throughout interactive system design. In Proceedings of the 7th ACM Conference on Designing Interactive Systems - DIS '08, 1-10. https://doi.org/10.1145/1394445.1394446

Norman, D. A. (1988), The Psychology of Everyday Things. New York, NY: Basic Books, Inc. 
Osborne, S. (2006) The New Public Governance?, in "Public Management Review”, 8 (3), pp. 377-388.

Osborne, S. (2011) From the New Public Management to Public Governance, Cheltenham: Edward Elgar.

Osborne, S. P., and Strokosch, K. (2013). It Takes Two to Tango? Understanding the Coproduction of Public Services by Integrating the Services Management and Public Administration Perspectives, in "British Journal of Management", 24(S1), S31-S47.

Osborne, S, Radnor, Z and Strokosch, K. (2016), Co-production and the Co-creation of Value in Public Services: A Suitable Case for Treatment?, in "Public Management Review", 18 (5), 639 653. DOI: 10.1080/14719037.2015.1111927.

Ozanne, L. (2010) 'Learning To Exchange Time: Benefits and Obstacles To Time Banking' International Journal of Community Currency Research 14 (A) 1-16 DOI:http://dx.doi.org/10.15133/j.jjccr.2010.002

Paletti, A. (2016), Co-production Through ICT in the Public Sector: When Citizens Reframe the Production of Public Services. In Caporarello, L., Cesaroni, F., Giesecke, R. and Missikoff, M. (eds), Digitally Supported Innovation, vol. 18, pp. 141-152. https://doi.org/10.1007/978-3-31940265-9_10

Paletti, A. (2018), How toManage ICTs Mediated Co-production: A Public Value Perspective, in "Proceedings of the 51st Hawaii International Conference on System Sciences".

Parks, Roger B., et al., (1981), Consumers as Co-Producers of Public Services: Some Economic and Institutional Considerations, in "Policy Studies Journal", 9, pp. 1001-1011

Parks, Roger B., et al., (1999), Ch. 17 in Local Public Economies. Readings from the Workshop in Political Theory and Policy Analysis, McGinnis, Michael d. (ed.); Ann Arbor, MI: University of Michigan Press.

Christos Perentis, Michele Vescovi, Chiara Leonardi, Corrado Moiso, Mirco Musolesi, Fabio Pianesi, and Bruno Lepri. 2017. Anonymous or Not? Understanding the Factors Affecting Personal Mobile Data Disclosure. ACM Trans. Internet Technol. 17, 2, Article 13 (March 2017), 19 pages. DOI: https://doi.org/10.1145/3017431

Pestoff, V. (2011). Citizens and Co-Production of Welfare Services: Childcare in Eight European Countries, in Pestoff V., Drandsen T. and Verschuere B. (eds), New Public Governance, the Third Sector, and Co-Production, London: Routledge.

Pestoff, V. 2012. "Co-production and Third Sector Social Services in Europe: Some Concepts and Evidence." Voluntas 23 (4):1102-1118. doi: 10.1007/s11266-012-9308-7

Rønning, R., Enquist, B. and Fuglsang, L. (2013). Framing Innovation in Public Service Sectors, London: Routledge. 
Rosson, M. B., and Carroll, J. M. (2002), Scenario-based Design, in "The Human-Computer Interaction Handbook: Fundamentals, Evolving Technologies and Emerging Applications", Lawrence Erlbaum Associates.

Sicilia, M., Guarini, E., Sancino, A., Andreani, M., and Ruffini, R. (2016), Public services Management and Co-production in Multi-Level Governance Settings, in "International Review of Administrative Sciences", 82(1), 8-27.

Sicilia, M., Sancino, A., Nabatchi, T. and Guarini, E. (2019), Facilitating Co-production in Public Services: Management Implications from a Systematic Literature Review, in "Public Money \& Management", First View, DOI: 10.1080/09540962.2019.1592904.

Sorrentino, M., Sicilia, M.Howlett, M. (2018). Understanding co-production as a new public governance tool, Policy and Society, 37:3, 277-293.

Vlachokyriakos V., Crivellaro C., Wright P., Karamagioli E., Staiou E.-R., Gouscos D., Thorpe R., Krüger A., Schöning J., Jones M., Lawson S., and Olivier P. 2017. HCl, Solidarity Movements and the Solidarity Economy. In Proceedings of the $2017 \mathrm{CHI}$ Conference on Human Factors in Computing Systems (CHI '17). ACM, New York, NY, USA, 3126-3137. DOI: https://doi.org/10.1145/3025453.3025490

Volkoff, O., and Strong, D. (2017), Affordance Theory and How to Use it in IS Research, in The Routledge Companion to Management Information Systems, New York: Routledge.

Vargo, S.L. and Lusch, R.F. (2006). The Service Dominant Logic of Marketing: Dialog, Debate, and Directions, M. E. Sharpe, Inc.

Wang, T.D. and Emurian, H.H. (2005) An Overview of Online Trust: Concepts, Elements, and Implications. Computers in Human Behavior, 21, 105125.DOI:http://dx.doi.org/10.1016/j.chb.2003.11.008

Webster, C. W. R., and Leleux, C. (2018). Smart Governance: Opportunities for TechnologicallyMediated Citizen Co-production, Information Polity, 23(1), 95-110. https://doi.org/10.3233/IP170065. 